\title{
DESIGN OF A DOWNSTREAM MIGRATION FISH PASS FOR EXISTING HYDROPOWER PLANTS
}

\author{
MACHIELS O. ${ }^{(1)}$, ERPICUM S. ${ }^{(2)}$, PIROTTON M. ${ }^{(2)}$, ARCHAMBEAU P. (2) \& THEUNISSEN P. ${ }^{(3)}$ \\ (1) Arcadis, Liege, Belgium, \\ olivier.machiels@arcadis.com \\ (2) HECE, Liege University, Liege, Belgium, \\ s.erpicum@uliege.be \\ (3) Luminus, Seraing, Belgium, \\ pierre.theunissen@edfluminus.be
}

\begin{abstract}
This paper focuses on the research and development conducted in order to design downstream fish passages along 2 sites equipped with a gated dam, locks and a hydropower plant. This study has been done by combining the input of on-site biological studies, hydrodynamic modelling, scale physical modelling, as well as considerations about constructability in the narrow spaces available on these existing sites. The proposed fish passages have been designed considering the local hydrodynamics and the expected fish response at each stage (attraction, caption, still area, transfer and release). On-site fish tracking enables to define the probability of location close to the water intakes. Numerical modelling then highlighted the correlation between hydrodynamics and fish behavior. It also provided the influence area and boundary conditions for the scale physical models representing in details the 3D flow fields around the proposed solutions, and their attractiveness. From the fish caption to the downstream release, the design of the fish passage has been realized according to the literature on biological behavior of salmo salar along such structures. Parallel, the technical constraints of existing plants have been challenged to define the best solutions. Finally, the interaction with existing or planned upstream fish ways has been analyzed to validate the design to be built on site in the coming months.
\end{abstract}

Keywords: Fish passage, hydraulic modelling, composite modeling, hydropower plant, fish attraction

\section{INTRODUCTION}

Downstream migration of threatened species such as Salmo Salar are key for hydropower plant (HPP) managers as well as for river managers. In Belgium, this specie is of main importance and a dedicated program Saumon 2000 has been initiated since 1987 to favor the reintroduction and the upstream migration of salmons. An European program (Life4Fish) has been recently initiated, enabling to develop several solutions to facilitate the downstream passage of salmon smolts and silver eels along 6 hydropower plants of the Meuse River in Belgium. The project considers turbine replacement, predictive models, behavioral barriers and downstream fish passages. This paper focused on the research and development conducted in order to design downstream fish passages along 2 pilot sites.

\section{PILOT SITES}

Among the 6 HPPs concerned by the Life4Fish project, pilot sites have been chosen in order to test the various solutions developed to enhance the downstream migration of the targeted species. Predictive downstream migration models will be tested on Andenne HPP for eels and on Monsin HPP for salmons. Behavioural barriers linked to the fish passages presented hereabove will be tested for both species on GrandsMalades and Ivoz-Ramet sites.

The Grands-Malades site is composed of a gated dam ( 5 gates $24 \mathrm{~m}$ wide with a chute of $4 \mathrm{~m}$ ), a lock ( $25 \mathrm{~m}$ $x 200 \mathrm{~m}$ ) and the HPP (4 Straflo groups of $40 \mathrm{~m}^{3} / \mathrm{s}$ ). A small fish ladder $\left(0.03 \mathrm{~m}^{3} / \mathrm{s}\right.$ ) is present on the left bank but its efficiency seems low according to its position and its dimensions. Mean discharge of the Meuse river at Grands-Malades is $206 \mathrm{~m}^{3} / \mathrm{s}$. 


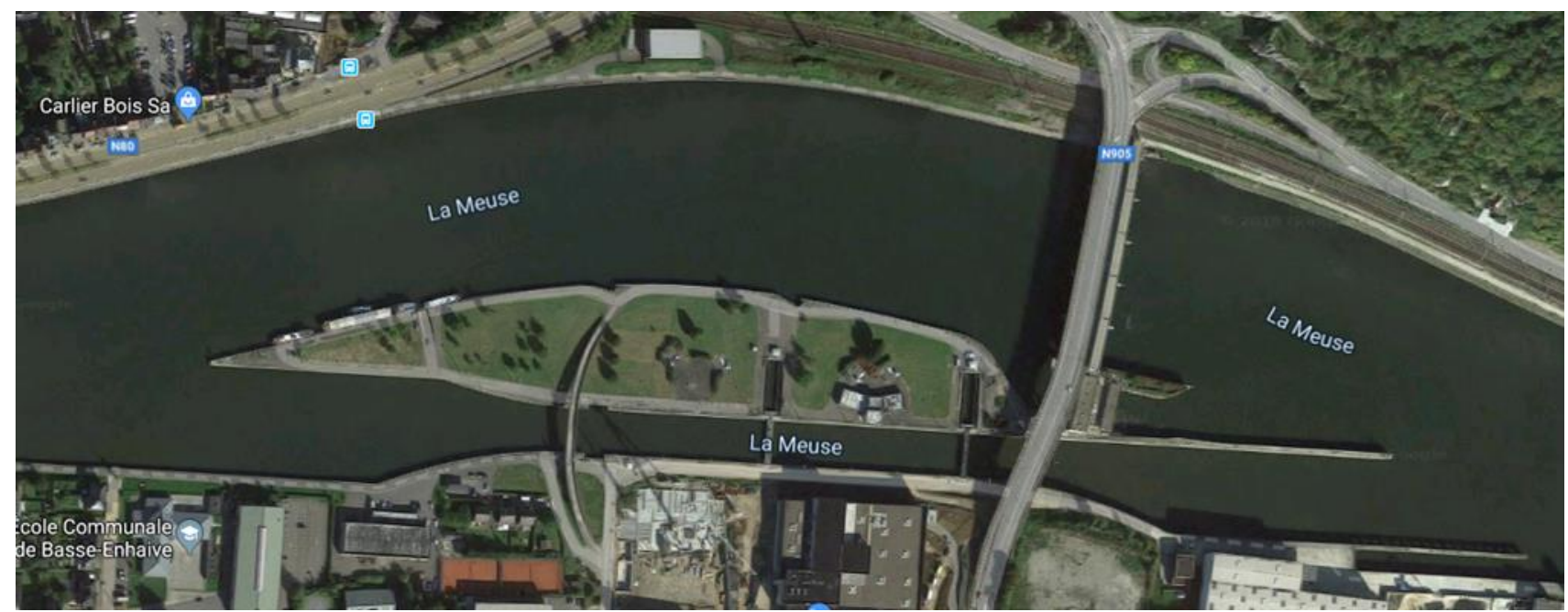

Figure 1. Plan view of the Grands-Malades site (@2019 Google)

The Ivoz-Ramet site is composed of a gated dam ( 5 gates $26 \mathrm{~m}$ wide with a chute of $4.6 \mathrm{~m}$ ), 2 locks ( $24 \mathrm{~m} x$ $240 \mathrm{~m}$ and $14 \mathrm{~m} \times 135 \mathrm{~m})$ and the HPP (3 vertical Kaplan groups of $\left.95 \mathrm{~m}^{3} / \mathrm{s}\right)$. A plunging concrete beam $(0$ to $1 \mathrm{~m}$ below the water surface) is located at the entrance of the inlet channel of the HPP. An upstream fish ladder is on the island between the dam and the HPP. It is composed of a surface channel allowing fish upstream migration $\left(0.66 \mathrm{~m}^{3} / \mathrm{s}\right)$ and a concrete channel passing under the first one allowing the passage of the attractive discharge $\left(3 \mathrm{~m}^{3} / \mathrm{s}\right)$. Mean discharge of the Meuse river at Ivoz-Ramet is $209 \mathrm{~m}^{3} / \mathrm{s}$.

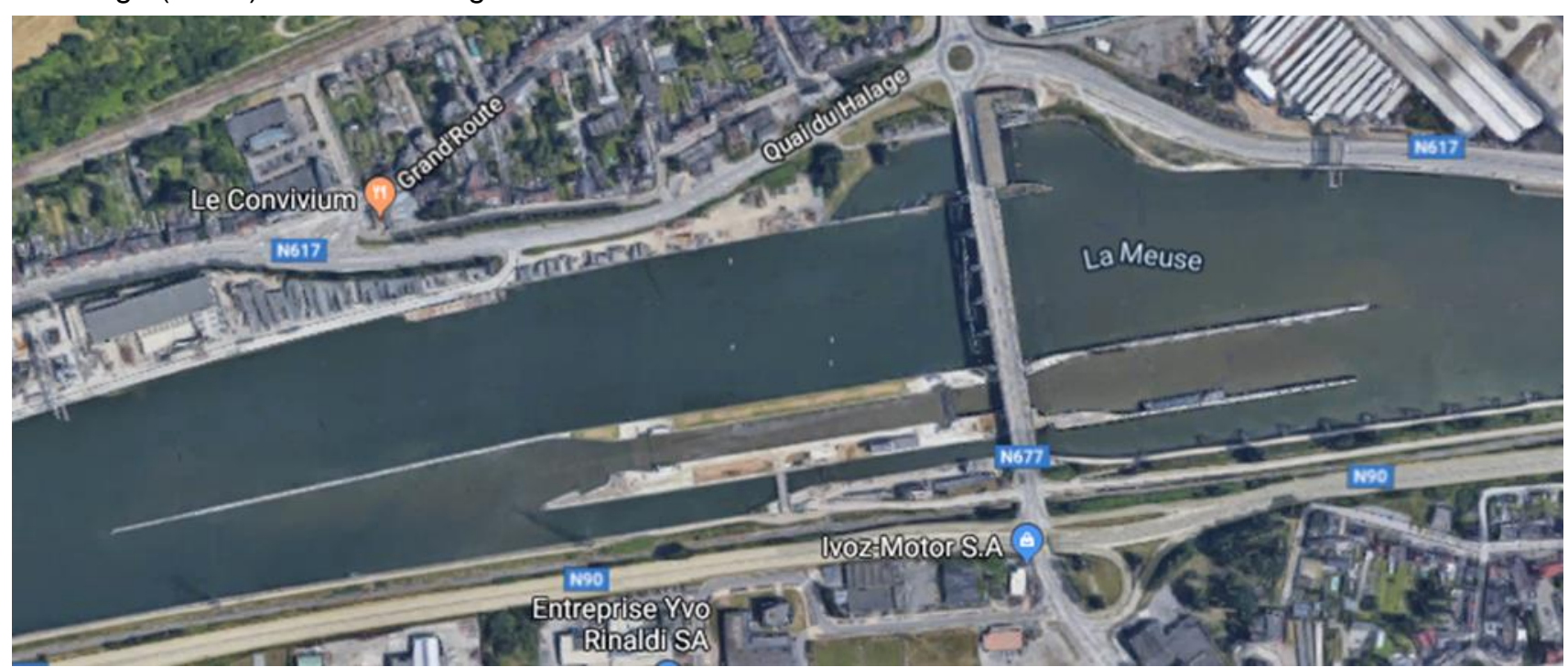

Figure 2. Plan view of the Ivoz-Ramet site (@2019 Google)

\section{DESIGN CRITERIA}

3.1 Fish location and flow conditions

A network of hydrophones located in the intake channel (Grands Malades) or upstream of the plunging beam at the entrance of the intake channel (Ivoz Ramet) has been used by Profish company to track in 2D (horizontal plane) the movements of salmon smolts approaching both HPP (Roy et al, 2018). The survey took place from April 14th to May 22th 2017 (Grands Malades - 38 days) and April 21th to May 3rd 2017 (Ivoz Ramet - 12 days). 47 smolts (resp. 14) were observed in Grands Malades (resp. Ivoz Ramet) with a mean residence time of $42 \mathrm{~min}$ (resp. $70 \mathrm{~min}$ ).

Maps have been built from the survey data to quantify the density of presence of the fishes upstream of the HPP (Figure 3). These maps have been built on the same grid as the one used to model, with the solver WOLF2D, the hydrodynamic conditions during the observation periods.

This analysis showed preferential areas where the smolts are looking for a way to swim downstream when they arrive close to the HPP. These areas remain the same whatever the general flow conditions in the Meuse 
river or the lock/dam operation during the survey period (drought conditions with a mean discharge around 70 $\mathrm{m}^{3} / \mathrm{s}$ in the river and regular locks operation at both sites).
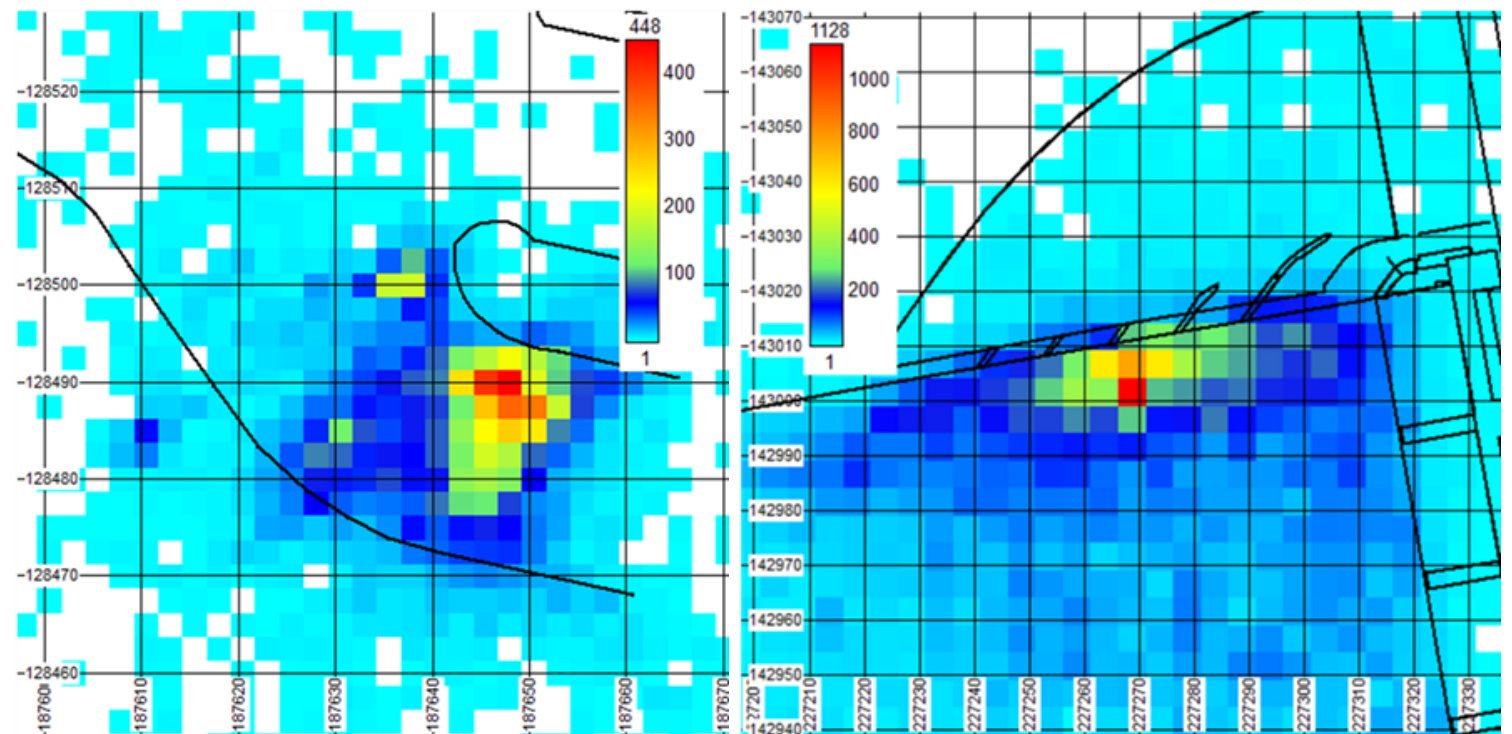

Figure 3. Density maps at Grands Malades (left) and lvoz Ramet (right) related to salmon smolts locations

At both sites, the areas of smolts preferred locations correspond to areas of higher flow velocity (Figure 4).

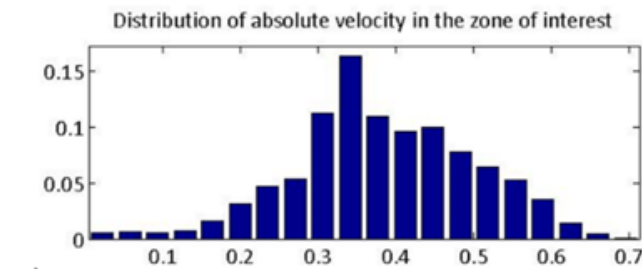

a)

Distribution of absolute velocity in the presence of smolts

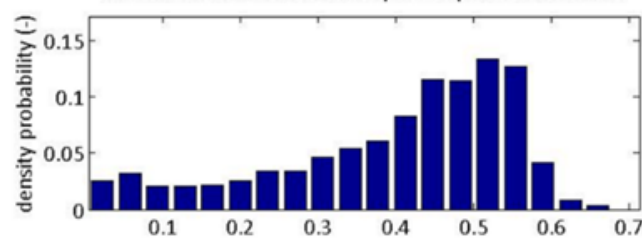

b)

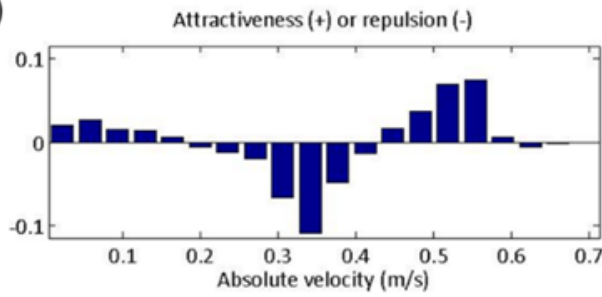

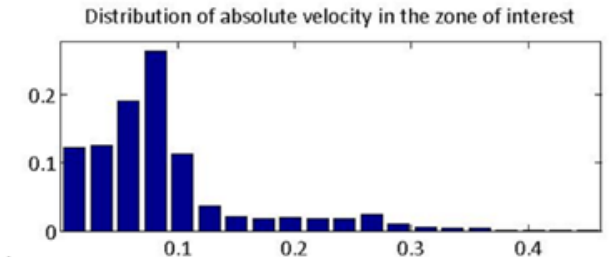

a)

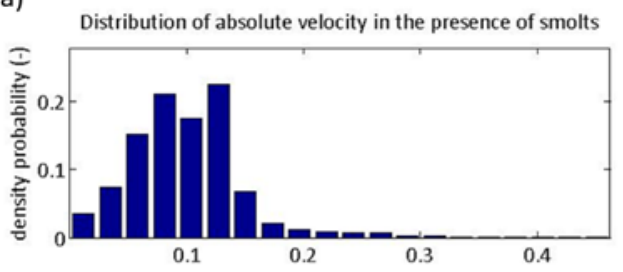

b)

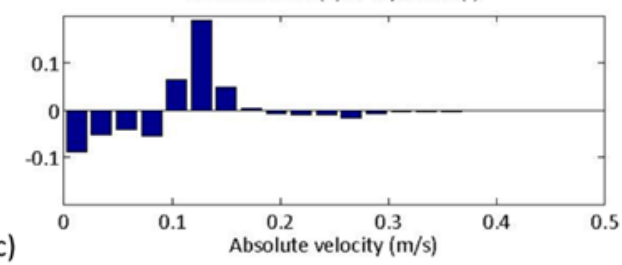

Figure 4 : Probability density distributions (a) in the zone of survey, (b) in the presence of smolts and (c) attractiveness/repulsion regarding flow velocity at Gands Malades (left) and Ivoz Ramet (right) HPP

\subsection{Entrance}

The bypass for juvenile salmonids generally consists of a rectangular opening located at the surface, whose dimensions are related to discharge. Minimum bypass dimensions (width and water depth at the entrance) are based upon the behavior of the fish which are reluctant to pass through devices which are too narrow and too shallow. For juvenile salmon a minimum of $0,5 \mathrm{~m}$ is recommended for both of these dimensions (Larinier and Travade 1999).

Hydraulic conditions at the entrance of the outlet are essential for its effectiveness. Larinier and Travade (1999) highlighted that when the flow velocity increase is too sharp, the fish experiences a repulsion to let down. They recommend a moderate and gradual acceleration at the entrance of the outlet. To achieve this goal, the flow control is created using a broad crested weir or a valve, preferably to a sharp crest that induces intense velocity gradients. The Pointis HPP bypass on the Garonne River (France) presents a longitudinal profile designed to obtain a gradual acceleration limited to $1 \mathrm{~m} / \mathrm{s} / \mathrm{m}$ (Chorda and Larinier 1996). It has a rounded upper 
part, then a facing inclined slope at $25^{\circ}$, followed by a horizontal platform playing the role of broad crested weir. This design has been used as a basis for our bypass design.

The maximum flow velocity at which Atlantic salmon smolts can remain in front of the screens for a sufficient time is about $0.5 \mathrm{~m} / \mathrm{s}$ (Larinier and Travade 1999). As the goal of the entrance is to capture the fish within the bypass, this is the minimal velocity to create at the entrance near the grid.

According to these assumptions, 4 design criteria have been established :

- Minimal water depth: $0.5 \mathrm{~m}$ (corresponding to a minimal water head of $0.75 \mathrm{~m}$ )

- Minimal width: $0.5 \mathrm{~m}$

- Entrance velocity: between $0.5 \mathrm{~m} / \mathrm{s}$ and $1 \mathrm{~m} / \mathrm{s}$

- Maximal velocity gradient: $1 \mathrm{~m} / \mathrm{s} / \mathrm{m}$

\subsection{Transfer}

Whenever possible, it is advised to create a drop of at least $0.5 \mathrm{~m}$ at the entrance of the transfer channel in order to prevent the upstream escape of the fishes (ASCE, 1995). 2003).

Transfer channel minimal dimensions of $0.6 \mathrm{~m}$ and minimal curve radius of $3 \mathrm{~m}$ must be observed (Amaral

Velocity along the transfer channel and at the impact point in the tailbay must remain less than 7 to $8 \mathrm{~m} / \mathrm{s}$ (ASCE, 1995). Experiments have shown that, whatever the size of fish, significant damage occurs (injuries to the gills, eyes and internal organs) when the impact velocity on the water surface exceeds $15-16 \mathrm{~m} / \mathrm{s}$ (BELL and DELACY, 1972). Odeh and Orvis (1998) proposed a minimal downstream depth of a quarter of the drop height with a minimum of $1 \mathrm{~m}$.

According to that, a stilling basin will be installed directly downstream the entrance device. It has been designed following 2 criteria :

- Minimal drop height: $0.5 \mathrm{~m}$

- Minimal water depth: $1 \mathrm{~m}$

Then a transfer channel has been designed according to 3 criteria:

- Minimal dimensions (width, diameter): $0.6 \mathrm{~m}$

- Minimal curve radius: $3 \mathrm{~m}$

- Maximal flow velocity: $7 \mathrm{~m} / \mathrm{s}$

\section{MODELING}

4.1 Approach flow conditions

The best location and design of the downstream fish passages intake have been defined in two steps. First, numerical modeling has been performed at the scale of the Meuse river reach upstream of the HPP in order to quantify the attraction of the fish passages intake depending on its location and the diverted discharge. Second, the best locations of the fish passages intakes have been reproduced on a physical scale model of the close area upstream of the HPP in order to optimize its design and to validate its attraction potential.

The fish passages have been designed in order to create surface currents oriented towards the passages intake in the areas of smolts preferred location identified based on the on-site survey (see section 3.1). Following discussions with the project partners, the location of the fish passages intake has been choosen considering a worst-case hydraulic scenario, i.e. all the turbines in operation at equipment without release of water at the mobile dams (full river discharge diverted to the HPP). In this case, discharge at Grands maladies is $161 \mathrm{~m}^{3} / \mathrm{s}$. It is $285 \mathrm{~m}^{3} / \mathrm{s}$ at Ivoz Ramet.

Two discharges diverted to the fish passages have been considered at each site. They correspond to the discharge creating an annual loss of hydropower production of $2 \%$ or $5 \%$. This represents $3.4 \mathrm{~m}^{3} / \mathrm{s} \mathrm{or} 7.3 \mathrm{~m} 3 / \mathrm{s}$, respectively, at Grands-Malades (2\% or $4.5 \%$ of the turbines discharge) and $2.9 \mathrm{~m}^{3} / \mathrm{s}$ or $7.1 \mathrm{~m}^{3} / \mathrm{s}$ at Ivoz-Ramet ( $1 \%$ or $2.5 \%$ of the turbines discharge). Several fish passages locations and fish passages intake widths have been considered with the numerical model. The effectiveness of fish passages location and geometry was assessed in the numerical model considering the extent of the flow velocity fields directed towards the fish passage intake. Numerical modeling showed that, at Grands Malades, the best location for the fish passage intake is on the left bank of the HPP intake channel, close to the mask wall just upstream of the turbines. Given the curved shape of the side wall on the left bank, a narrow opening of the fish passage intake is preferable, with a diverted discharge of $3.4 \mathrm{~m}^{3} / \mathrm{s}$ (smaller one). At Ivoz Ramet, the best location is on the right side of the surface beam at the entrance of the HPP intake channel, with a wide fish passage intake and the discharge of $7.1 \mathrm{~m}^{3} / \mathrm{s}$ (larger one - Figure 5).

These locations and geometries creating the best attraction conditions in the area of smolts presence were reproduced on the scale physical models (1:25 scale for Grands Malades HPP and 1:35 scale for Ivoz Ramet HPP). On the physical models, $0.02 \mathrm{~m}$ diameter floats were used to verify the attraction of the tested fish 
passages intakes geometry. For both cases, geometric optimization of the fish passages intakes enable to drastically improve their ability to attract floats coming from the Meuse river upstream.

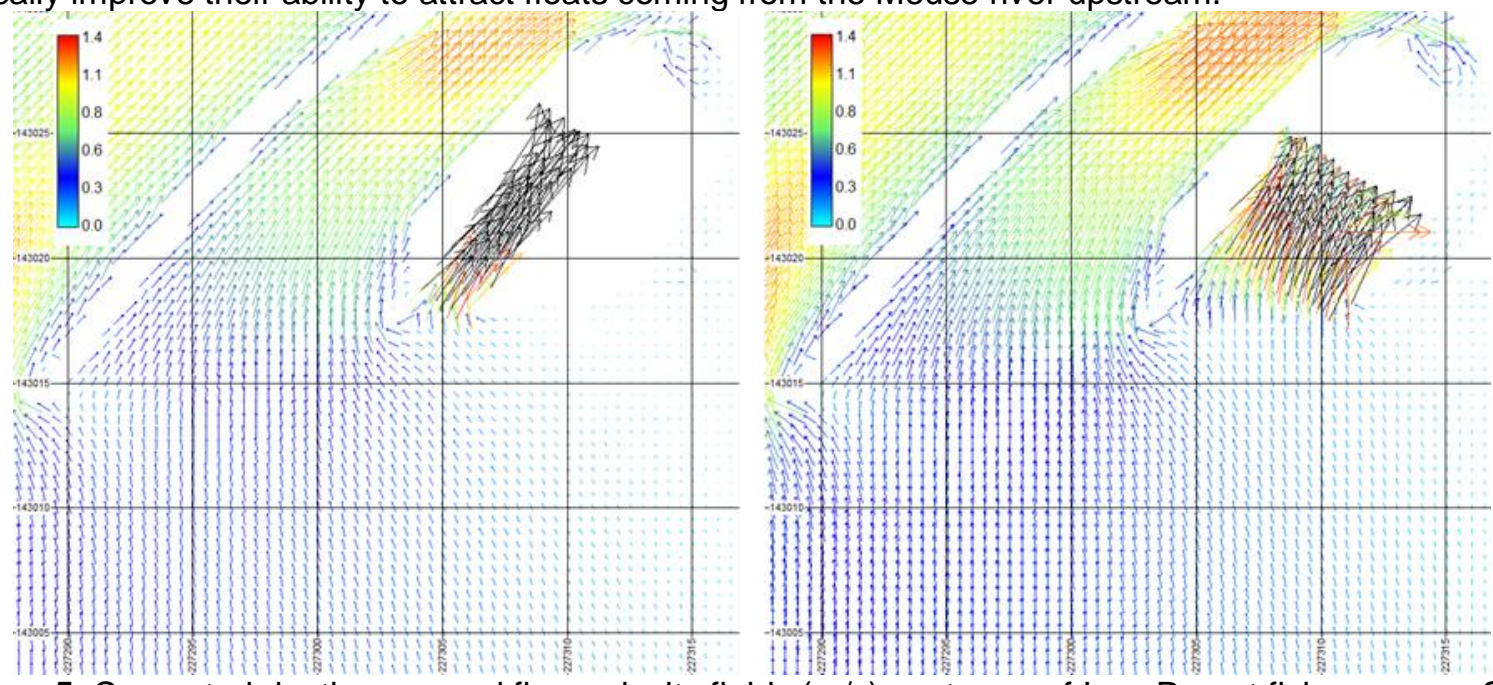

Figure 5. Computed depth averaged flow velocity fields ( $\mathrm{m} / \mathrm{s}$ ) upstream of Ivoz Ramet fish passage. Small intake width and diverted discharge (left) and large intake width and diverted discharge (right)

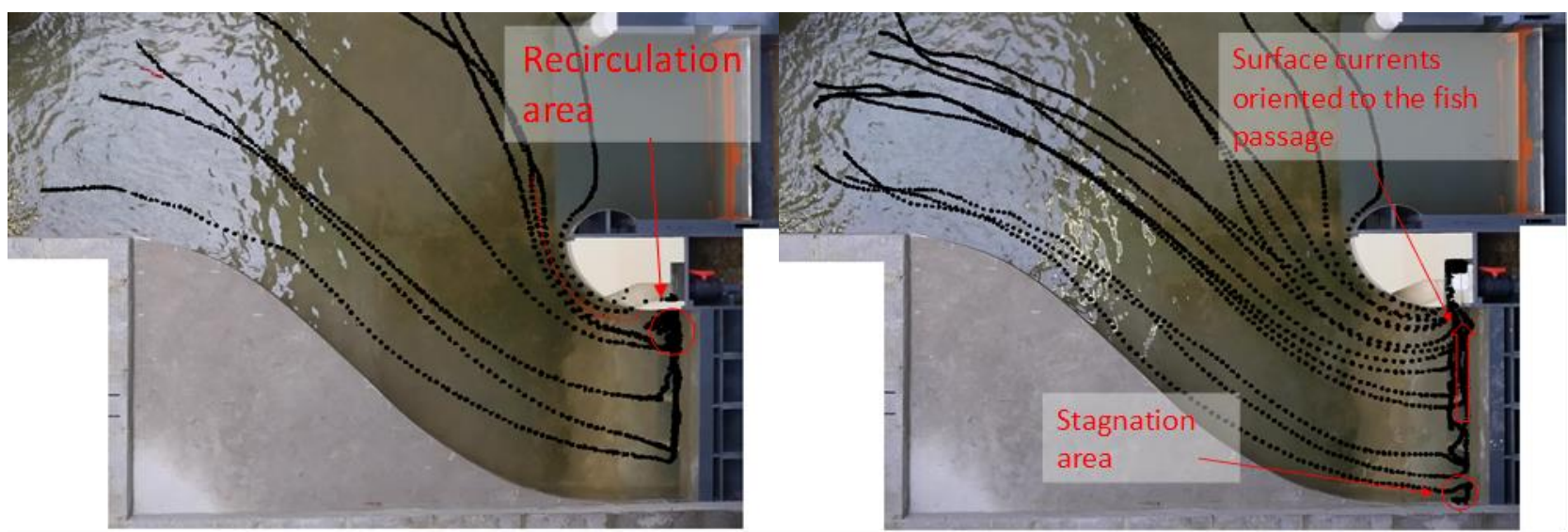

Figure 6. Observed floats trajectories upstream of Grands Malades HPP fish passage. Initial fish passage design (left) and optimized one (right)

\subsection{Energy dissipation along the fish passage}

1D free surface flow modeling (Figure 7) has been performed along both fish passage to verify the former design rules as well as to evaluate the range of energy dissipation along the structure. On both sites the energy dissipation is mainly assumed downstream of the entrance weir and at the downstream end of the channel.
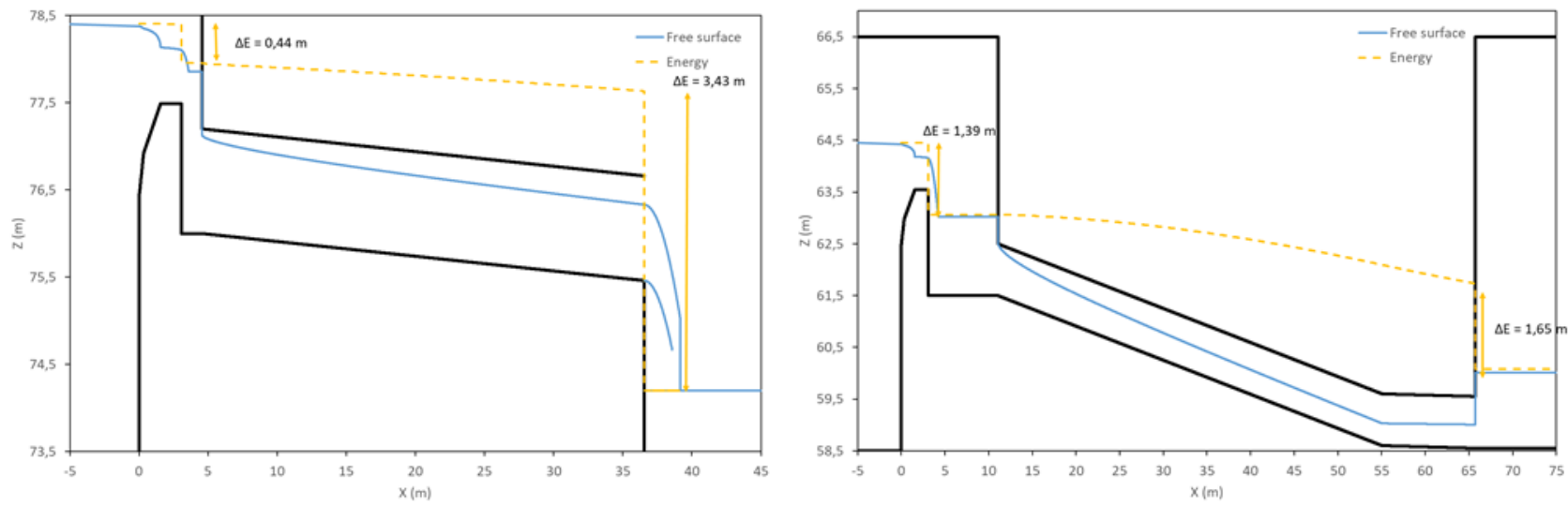

Figure 7. 1D free surface modeling. Grands-Malades (left) and Ivoz-Ramet (right) fish passages 
In Grands-Malades, a drop of the energy line of $0.44 \mathrm{~m}$ within the stilling basin is observed. It corresponds to $1933 \mathrm{~W}$ to dissipate within a volume of $9.5 \mathrm{~m}^{3}\left(204 \mathrm{~W} / \mathrm{m}^{3}\right)$. A second drop of $3.43 \mathrm{~m}$ is observed within the free fall downstream of the transfer channel. This corresponds to $14,957 \mathrm{~W}$ to dissipate in the large volume of the downstream channel of the plant (water depth $=5 \mathrm{~m}$ ).

In Ivoz-Ramet, the drop of energy within the stilling basin is of $1.39 \mathrm{~m}(9,063 \mathrm{~W})$ to dissipate in a volume of $41 \mathrm{~m}^{3}\left(221 \mathrm{~W} / \mathrm{m}^{3}\right)$. The second drop of energy of $1.65 \mathrm{~m}(10,790 \mathrm{~W})$ is dissipated within the hydraulic jump observed at the entrance of the downstream stilling basin of the existing fish ladder. This stilling basin has a volume of $55 \mathrm{~m}^{3}$. The energy dissipation is thus $196 \mathrm{~W} / \mathrm{m}^{3}$.

For fish ladder resting pools design, a criteria of energy dissipation below $200 \mathrm{~W} / \mathrm{m}^{3}$ is recommended. The predicted for the proposed designs should be acceptable to allow a safe downstream fish passage.

The 1D free surface modeling enables also the verification of the design criteria on flow velocity and water depth. In Grands-Malades, the maximal velocity is $5 \mathrm{~m} / \mathrm{s}$ and the minimal depth is $0.87 \mathrm{~m}$. In Ivoz-Ramet, the maximal velocity is $7.7 \mathrm{~m} / \mathrm{s}$ and the minimal depth is $0.43 \mathrm{~m}$.

\section{FINAL DESIGN}

The main issue to design fish passages in an already built area is the constraints on available space. These spaces are very narrow at both pilot sites considered in this study. On both sites, the final design has been defined respecting the structural components of the power plant (including trash racks and machinery), the dam (including gates machinery) and the road bridge. Furthermore in Ivoz-Ramet the available space is already largely used by the existing upstream fish ladder. In Grands-Malades, it has been verified that the proposed design allow the installation of an upstream fish ladder to be built in the future.

According to these constraints, it has been decided to use the attraction discharge of the upstream fish ladder to feed the downstream passage. In Ivoz-Ramet (Figure 8) the solution consists thus to build the passage intake along the existing side wall and the stilling basin on the island between the dam and the plant. The stilling basin is than directly connected to the existing channel under the upstream fish ladder, which currently transfer the attraction discharge.

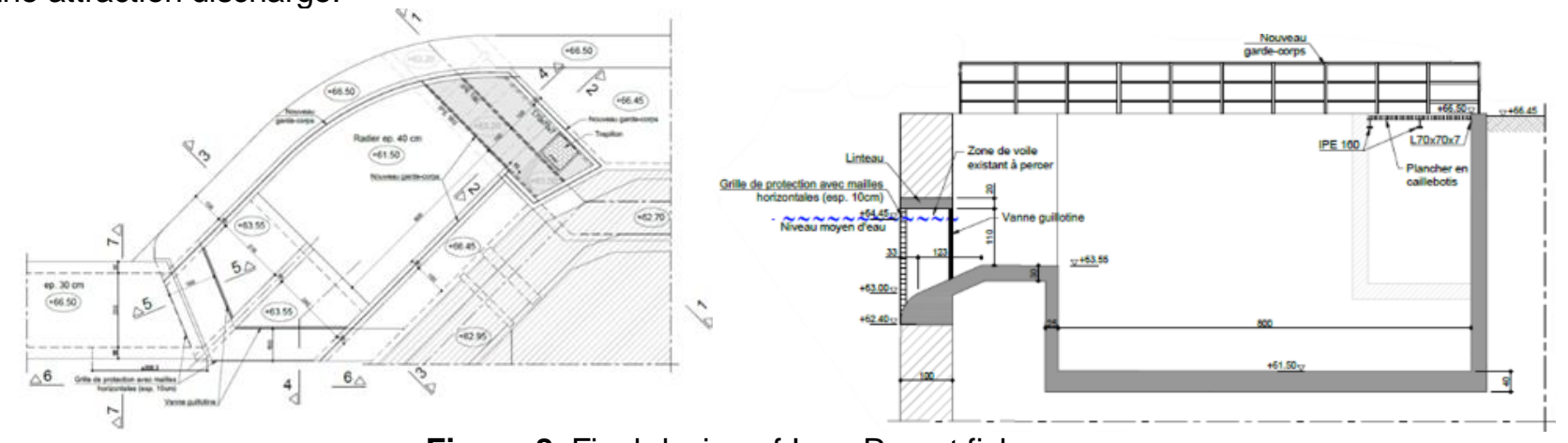

Figure 8. Final design of Ivoz-Ramet fish passage

In Grands-Malades (Figure 9), the stilling basin is shorter according to the limited available place upstream of the trash rack and the necessity of a $90^{\circ}$ angle between the intake and the transfer channel. The transfer to downstream is done by a $1.2 \mathrm{~m}$ diameter pipe that first discharge freely in the downstream channel of the plant. In the future, this pipe will be linked to the most downstream resting pool of the fish ladder to be built. 

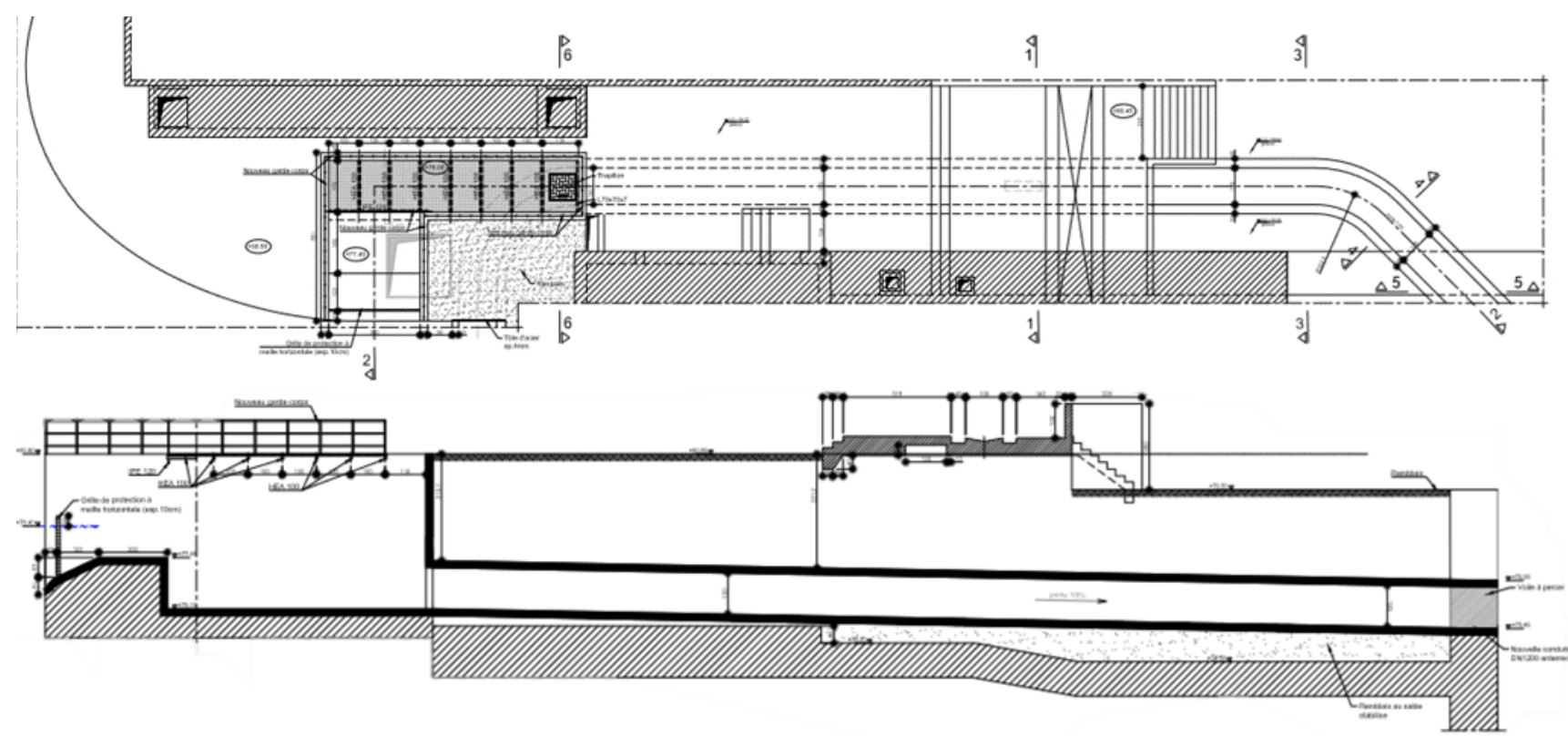

Figure 9. Final design of Grands-Malades fish passage

According to these final designs, the discharge of the fish passage will be $4.44 \mathrm{~m}^{3} / \mathrm{s}$ and $6.67 \mathrm{~m} 3 / \mathrm{s}$ respectively for Grands-Malades and Ivoz-Ramet sites. This correspond to about $2.5 \%$ of the installed discharge of the plant on both sites.

\section{CONCLUSION}

In the general framework of salmon smolts protection in dammed rivers, the design of dedicated fish passages beside the obstacles such as hydropower plants seems to be a key solution to improve a safe downstream fish migration while preserving green and renewable energy production. On the lower reach of the Meuse river in Belgium, an undergoing projects aims at improving downstream migration of salmon smolts by creating suitable passage solution at 6 hydropower plants. In this scope, two pilot sites have been identified to test solutions.

At both pilot sites, a site survey has been performed to assess downstream migrating salmon smolts behavior when they approach the site. Besides, hydraulic modelling has then been performed using the complementary approaches of $1 \mathrm{D}$ and $2 \mathrm{D}$ numerical as well as $3 \mathrm{D}$ experimental modelling (composite modelling). Results of hydraulic modelling have been used to analyze the correlation between hydraulic parameters and fishes' behavior as well as to design the downstream passages. For both sites, considering constraints on diverted discharge and for the worst case of HPP operation, an optimized geometry of the fish passage intake able to create significant surface currents to the desired direction has been defined using large scale numerical modelling and local physical scale models. The hydraulic characteristics (velocity, water depth, energy dissipation) enabling a safe fish transfer to downstream have been verified along the 3 components of the fish passage (entrance, stilling basin, transfer channel) with a 1D free surface flow modeling.

The final design proposed on both sites is based on the co-existence with upstream fish ladders enabling to exploit the attractive discharge of the last one to allow downstream migration within the very narrow spaces available on such already built area.

These solutions will be built in the coming months and their efficiency will be assessed by a new site survey in the scope of the undergoing project.

\section{ACKNOWLEDGEMENTS}

This work is carried out within the Life4Fish program (LIFE16 NAT/BE/000807 LIFE4FISH) co-financed by the European Commission.

The Authors would like to thank Mr Max Mathieu for building and partly operating both scale physical models at HECE Laboratory.

\section{REFERENCES}

Amaral, S. (2003). The use of angled bar racks and louvers for guiding fish at FERC-licensed projects. Presented at FERC fish passage protection workshop. Alden research laboratory, Inc., Holden, MA. 
ASCE (1995). Guidelines for design of intakes for hydroelectric plant. American Society of Civil Engineers, New York, 469-499.

Bell, M.C., and Delacy, A.C. (1972). A compendium on the survival of fish passing through spillways and conduits. Fish. Eng. Res. Prog., U.S. Arm y Corps of Eng., North Pacific Div., Portland, Oregon , $121 \mathrm{p}$.

Chorda, J., and Larinier, M. (1996). Dispositif de dévalaison des poissons migrateurs à la centrale de Pointis - Etude sur modèle réduit de l'exutoire de dévalaison. HYDRE $n^{\circ} 184$, GHAAPPE RA96.09.

Larinier, M., and Travade, F. (1999). La dévalaison des migrateurs : problèmes et dispositifs. Bulletin Français de la Pêche et de la Pisciculture, (353-354), 181-210.

Odeh, M., and Orvis, C. (1998). Downstream fish passage design considerations and developments at hydroelectric projects in the North-east USA. In : Jungwirth, M., Schmutz, S., and Weiss, S. (Eds.), Fish migration and fish bypasses, Fishing New Books, 267-280. Roy, R., Beguin, J., Watthez, Q., Goffaux, D., and Sonny, D. (2018). Suivi des smolts de saumon en migration au niveau du tronçon de la Meuse exploité par 6 centrales hydroélectriques. Rapport de synthèse v2.3, 81p. 